\title{
Application of Iron Oxide and Iron Oxide/Alumina Nanocomposites for Arsenic and Fluoride Removal: A Comparative Study
}

\author{
Prathna TC ${ }^{1}$, Saroj K Sharma ${ }^{1}$, Maria Kennedy ${ }^{1,2}$ \\ ${ }^{1}$ Environmental Engineering and Water Technology Department, IHE Delft Institute for Water Education \\ 2601 DA, Delft, The Netherlands \\ p.thanjavur@un-ihe.org; s.sharma@un-ihe.org \\ 2Faculty of Civil Engineering, Delft University of Technology \\ Stevinweg 1, 2628 CN, Delft, The Netherlands \\ m.kennedy@un-ihe.org
}

\begin{abstract}
The study provides a comparative analysis of As (III), As (V) and F removal by iron oxide nanoparticles and iron oxide/alumina nanocomposites. The nanoparticles were characterized by particle size, zeta potential and Scanning Electron Microscopic analysis which showed spherical iron oxide nanoparticles around $\sim 200 \mathrm{~nm}$ and nanocomposites around $\sim 300 \mathrm{~nm}$. Energy Dispersive Analysis $X$ ray Spectroscopic analysis confirmed the presence of $\mathrm{Fe}, O$ in iron oxide nanoparticles in addition to $\mathrm{Al}$ in the iron oxide/alumina nanocomposites. Batch sorption studies carried out at varying initial concentrations of As and $F$ revealed an enhanced $F$ and As sorption capacity for the nanocomposites when compared to the nanoparticles. The sorption isotherm showed that data for As (III), As (V) and F fitted best to Freundlich isotherm for both the type of nanoparticles. The maximum sorption capacity of iron oxide nanoparticles for As (III) and As (V) at pH 7 were $909 \mu \mathrm{g} / \mathrm{g}$ and $3333 \mu \mathrm{g} / \mathrm{g}$ while the comparative maximum adsorption capacity qm values for the nanocomposites were $1000 \mu \mathrm{g} / \mathrm{g}$ and $2500 \mu \mathrm{g} / \mathrm{g}$ respectively. The maximum $F$ sorption capacity of iron oxide nanoparticles was $1.47 \mathrm{mg} / \mathrm{g}$ while it was $4.82 \mathrm{mg} / \mathrm{g}$ for the nanocomposites. The preliminary results of the study showed that the iron oxide/alumina nanocomposites can be promising adsorbents for both As and F removal from small scale water systems.
\end{abstract}

Keywords: Iron Oxide, Alumina, Nanoparticles, Arsenic, Fluoride.

(C) Copyright 2018 Authors - This is an Open Access article published under the Creative Commons Attribution License terms (http://creativecommons.org/licenses/by/3.0). Unrestricted use, distribution, and reproduction in any medium are permitted, provided the original work is properly cited.

\section{Introduction}

Contamination of drinking water sources continues to pose a challenge in almost all parts of the world. The World Health Organization reports that around 748 million people around the world lack access to safe drinking water (1) and thus one of the Sustainable Development Goals (SDG 6) of the United Nations is to ensure universal access of safe drinking water to all by 2030 [2]. Groundwater consists of a number of naturally occurring and anthropogenic generated ions which may compromise water quality. Among the various inorganic contaminants in groundwater, arsenic and fluoride have been determined to be the contaminants most detrimental to human health [3]. Studies have indicated that two contaminants when ingested together may function independently, synergistically or antagonistically to one another (4). Studies have indicated the co-existence of both arsenic and fluoride in many aquifers and hence there is an urgent need to develop techniques to simultaneously remove both arsenic and fluoride $[5,6]$. The major challenge is to design and optimize a material which is safe and easy to use at both household and small community levels. This will ultimately play a significant role in reducing treatment cost.

Various materials have been tested as possible adsorbents for the removal of arsenic and fluoride from water, like alumina, iron based oxides, rare metal oxides, activated carbon, and bone char to name a few $[7,8]$. In recent decades, there has been an increased 
interest in the application of nanomaterials in environmental applications such as in contaminant removal or toxicity mitigation [9]. Iron oxide based materials are known for their affinity towards arsenic and fluoride removal while alumina is known for its efficient fluoride removal potential [10].

Therefore, in the present study, an attempt was made to compare the feasibility of iron oxide nanoparticles and iron oxide/alumina nanocomposites as adsorbents for removal of arsenic and fluoride. In order to achieve this, iron oxide nanoparticles and iron oxide/alumina nanocomposites were synthesized, characterized and their arsenic and fluoride removal efficiency studied.

\section{Materials and Methods}

\subsection{Synthesis of Iron Oxide Nanoparticles}

Briefly, $0.279 \mathrm{~g}$ of $\mathrm{FeCl}_{3} .6 \mathrm{H}_{2} \mathrm{O}$ and $1.395 \mathrm{~g}$ of $\mathrm{FeCl}_{2} .4 \mathrm{H}_{2} \mathrm{O}$ were dissolved in $100 \mathrm{~mL}$ ethanol to which $14.7 \mathrm{M} \mathrm{NH}_{3}$ (in the form of $\mathrm{NH}_{4} \mathrm{OH}$ ) was added dropwise until $\mathrm{pH}$ reached to 9 . The flask was placed at $50{ }^{\circ} \mathrm{C}$ for 3 hours under stirring and the contents were centrifuged and the pellet dried [11].

\subsection{Synthesis of Iron Oxide/Alumina Nanocomposites}

The method of Amirsalari et al. [12] was followed with modifications. Briefly, $3.75 \mathrm{~g}$ of $\mathrm{Al}\left(\mathrm{NO}_{3}\right)_{3} .9 \mathrm{H}_{2} \mathrm{O}$ was dissolved in $100 \mathrm{ml}$ of deionized water and the solution was heated to $60^{\circ} \mathrm{C}$. The solution was then precipitated by the addition of $\mathrm{NH}_{3}$ solution. To the obtained aluminium hydroxide gel, $0.05 \mathrm{~g}$ of prepared iron oxide nanoparticles were added and stirring was continued for $12 \mathrm{~h}$. The contents were then centrifuged and the pellet dried and calcined at $550 \stackrel{\circ}{\circ}$ for $3 h$.

\subsection{Physico Chemical Characterization}

Particle size analyser (Zetasizer Nano ZS, Malvern Instruments Ltd, UK) was used to determine the average particle size while zeta potential studies were used to study the point of zero charge. Scanning Electron Microscopy (JSM-6010LA, JEOL, USA Inc.) was carried out to determine the morphology of the nanoparticles. The dispersed particles were directly coated onto carbon tape and air-dried prior to analysis. Energy Dispersive $\mathrm{X}$ ray Analysis spectroscopy was performed to determine the elemental composition of the samples.

\subsection{Adsorption Studies}

Adsorption isotherm studies were performed at pH 7 at different initial concentrations for both arsenic and fluoride. Studies were carried out at $\mathrm{pH}$ 7. The bottles were continuously shaken at $180 \mathrm{rpm}$ (Innova 2100 Platform Shaker, New Brunswick Scientific, USA) for 4 hours at room temperature $\left(20^{\circ} \mathrm{C}\right)$.

The adsorption capacity was estimated by equation (1) as follows:

$q_{e}=\frac{\left(C_{o}-C_{e}\right) V}{m}$

where $\mathrm{q}_{\mathrm{e}}$ is the adsorption capacity $(\mathrm{mg} / \mathrm{g}), \mathrm{C}_{\mathrm{o}}$ and $\mathrm{C}_{\mathrm{e}}$ are the initial and equilibrium concentration $(\mu \mathrm{g} / \mathrm{L}$ and $\mathrm{mg} / \mathrm{L}$ for As (III, $\mathrm{V}$ ) and F respectively) of the contaminant respectively, $\mathrm{V}$ is the volume of As and $\mathrm{F}$ solution (L) and $\mathrm{m}$ is the mass of the iron oxide nanoparticle.

Langmuir and Freundlich isotherms were used to fit the adsorption data from equilibrium experiments. The Langmuir isotherm equation can be expressed as follows (Langmuir, 1916)

$\frac{C_{e}}{q_{e}}=\frac{1}{q_{m}} C_{e}+\frac{1}{k_{\propto} q_{m}}$

while the Freundlich model can as expressed as given in Eqn (3) (Freundlich, 1906).

$\log q_{e}=\log k_{f}+\frac{1}{n} \log C_{e}$

where $\mathrm{q}_{\mathrm{e}}$ is the amount of sorbate adsorbed at equilibrium per $g$ of iron oxide/alumina nanocomposites and iron oxide nanoparticles respectively; $\mathrm{C}_{\mathrm{e}}$ is the concentration of sorbate at equilibrium; $\mathrm{q}_{\mathrm{m}}$ is monolayer sorption capacity $(\mathrm{mg} / \mathrm{g})$; $\mathrm{k}_{\alpha}$ is the Langmuir sorption equilibrium constant and $\mathrm{k}_{\mathrm{f}}$ and $1 / n$ are the Freundlich constants.

\section{Results and Discussion}

Spherical nanoparticles of around $192 \pm 5.96 \mathrm{~nm}$ and $236 \pm 19.49 \mathrm{~nm}$ in diameter were observed for iron oxide nanoparticles and the iron oxide/alumina nanocomposites respectively. The surface charge_of an adsorbent is determined by the $\mathrm{pH}$ of the solution. Hence, the efficacy of an adsorbent in adsorbing contaminants will be affected by the $\mathrm{pH}$ of the solution [13]. Zeta potential analysis was carried out different 
$\mathrm{pH}$ ranges. In both cases, a decrease in surface zeta potential was observed with a corresponding increase in $\mathrm{pH}$. The studies revealed that point of zero charge was $\sim \mathrm{pH} 9$ and $\sim \mathrm{pH} 6.5$ for the nanoparticles and nanocomposites respectively (Figure 1). The method of synthesis plays a significant role in determining the corresponding zeta/surface potential of the particles. SEM microscopic analysis revealed nearly spherical iron oxide nanoparticles with a size range of $\sim 130 \mathrm{~nm}$ while the size of the iron oxide/alumina nanocomposites was in the range of $\sim 300$ to $\sim 350 \mathrm{~nm}$. EDAX analysis confirmed the presence of $\mathrm{Fe}, \mathrm{O}$ peaks for the iron oxide nanoparticles and in addition $\mathrm{Al}$ peaks for the alumina/iron oxide nanocomposites (Figure 2).

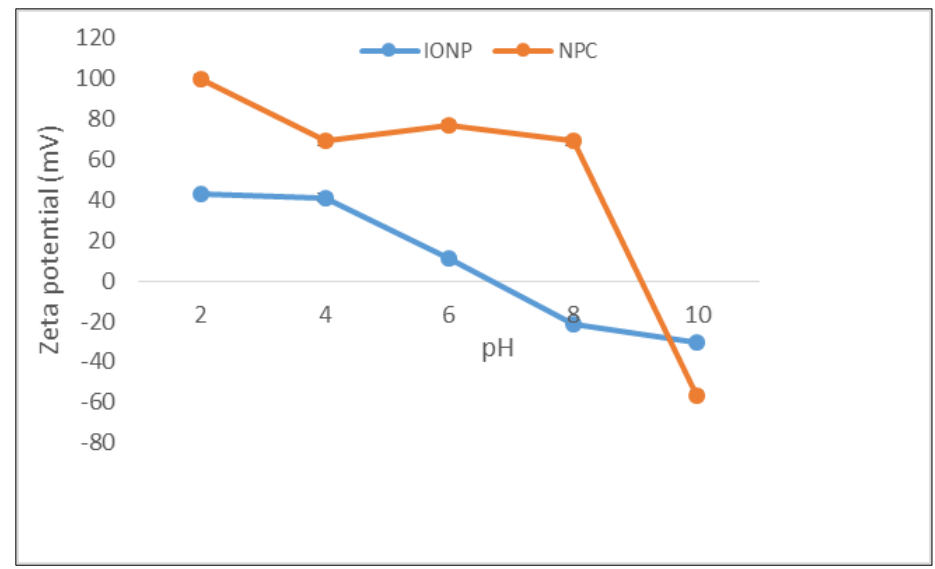

Figure 1. Point of zero charge of iron oxide nanoparticles (IONP) and iron oxide/alumina nanocomposites (NPC).

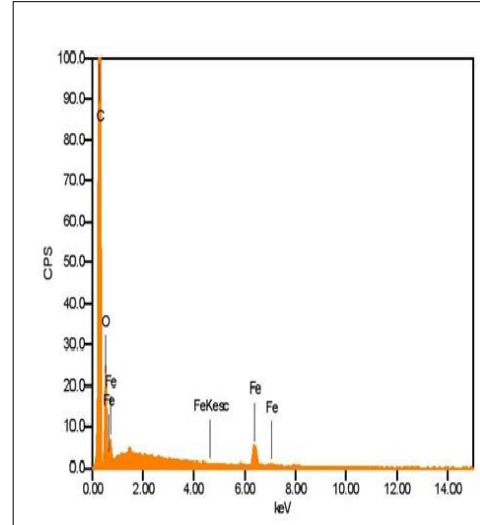

(a)

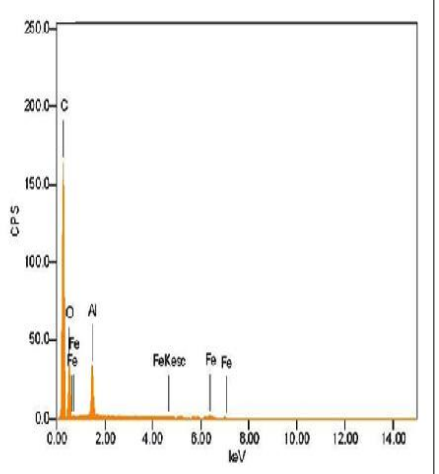

(b)
Figure 2. EDAX analysis of (a) iron oxide nanoparticles (IONP) and (b) iron oxide/alumina nanocomposites (NPC).

Sorption studies were performed at varying initial concentrations of fluoride and arsenic. In all cases, the adsorption capacity increased with increase in initial concentration of F and As (III), As (V) for both the iron oxide nanoparticles and the nanocomposites. An enhanced F sorption capacity was observed for the nanocomposites as compared to the iron oxide nanoparticles as was the case with As (III).

In order to further determine the mode of adsorption of the adsorbent, isotherm studies were carried out and the data was analysed. The data in all cases fitted well with the Freundlich isotherm. The $\mathrm{k}_{\mathrm{f}}$ values of the nanocomposites were significantly higher for As (V) (145.75 $\mu \mathrm{g} / \mathrm{g})$ as compared to iron oxide nanoparticles $(46.88 \mu \mathrm{g} / \mathrm{g})$. The $\mathrm{q}_{\mathrm{m}}$ values were nearly similar for As (III) for both the iron oxide nanoparticles and the nanocomposites. However, there was a significant increase in the $\mathrm{q}_{\mathrm{m}}$ values of the nanocomposites towards $\mathrm{F}(4.82 \mathrm{mg} / \mathrm{g}$ ) as compared to iron oxide nanoparticles $(1.47 \mathrm{mg} / \mathrm{g})$. The $\mathrm{q}_{\mathrm{m}}$ and $\mathrm{k}_{\mathrm{f}}$ values of the adsorbents towards As and $\mathrm{F}$ are tabulated in Table 1.

Table 1. Summary of parameters obtained from Freundlich and Langmuir isotherms for iron oxide nanoparticles and nanocomposites towards As (III), As (V) and F adsorption.

\begin{tabular}{|l|l|l|l|l|}
\hline \multirow{2}{*}{} & Freundlich & Langmuir \\
\cline { 2 - 5 } & $\mathbf{k}_{\mathbf{f}}(\boldsymbol{\mu g} / \mathbf{g})$ & $\mathbf{R}^{\mathbf{2}}$ & $\mathbf{q}_{\mathbf{m}}(\boldsymbol{\mu} \mathbf{g} / \mathbf{g})$ & $\mathbf{R}^{\mathbf{2}}$ \\
\cline { 2 - 5 } IONP & 25.35 & 0.93 & 909 & 0.68 \\
\hline NPC & 34.89 & 0.91 & 1000 & 0.83 \\
\hline & \multicolumn{5}{|c|}{ As (V) } \\
\hline IONP & 46.88 & 0.98 & 3333 & 0.98 \\
\hline NPC & 145.75 & 0.86 & 2500 & 0.61 \\
\hline & \multicolumn{5}{|c|}{$\mathbf{F}$} \\
\cline { 2 - 5 } & $\mathbf{k}_{\mathbf{f}}(\mathbf{m g} / \mathbf{g})$ & $\mathbf{R}^{\mathbf{2}}$ & $\left.\mathbf{q}_{\mathbf{m}} \mathbf{( m g} / \mathbf{g}\right)$ & $\mathbf{R}^{\mathbf{2}}$ \\
\hline IONP & 0.78 & 0.64 & 1.47 & 0.48 \\
\hline NPC & 1.19 & 0.92 & 4.82 & 0.86 \\
\hline
\end{tabular}

Results from Table 1 indicate that in almost all cases, nanocomposites exhibited higher adsorption capacity towards both arsenic and fluoride. Iron-based adsorbents have been extensively reported to exhibit the highest adsorption capability towards arsenic while aluminium based adsorbents have been shown to have affinity towards fluoride $[11,15]$. Nanocomposites thus synthesized using both iron oxide and alumina exhibited good adsorption towards both the contaminants. Further detailed studies on the simultaneous adsorption of arsenic and fluoride by iron oxide/alumina nanocomposites are currently underway. 


\section{Conclusions}

The present study showed nearly spherical iron oxide/alumina nanocomposites with an average particle size between 300 to $350 \mathrm{~nm}$ were synthesized. The iron oxide/alumina nanocomposites possessed optimum sorption capacity towards both arsenic and fluoride as compared to iron oxide nanoparticles. The iron oxide nanoparticles had a higher $\mathrm{q}_{\mathrm{m}}$ value towards As (V) but had poor sorption capacity towards $F$ as compared to the nanocomposites. Further detailed studies into the adsorption behaviour of iron oxide/alumina nanocomposites would be required in designing the nanocomposites as adsorbents for small scale water treatment systems for the simultaneous removal of fluoride and arsenic. One of the main challenges would be to determine an effective way to use the nanocomposites in the powdered form more effectively for point of use water treatment systems.

The idea to remove the ion-encapsulated nanocomposite is critically important. Otherwise, the ions will still remain within the system, this time in nanocomposite encapsulated form. Diale et al. (14) studied the sequestration of heavy metals from spent waste using natural zeolites. The same approach may be further explored for the sludge of spent nanoadsorbents. Further studies onto effective ways to solidify and stabilize the contaminant loaded nanocomposite, for e.g., into bricks, cement, immobilizing spent nanocomposites in polymeric matrices before being dumped in landfills etc. shall also be the way forward.

\section{Acknowledgements}

This research was funded by the People Programme (Marie Curie Actions) of the European Union's Seventh Framework Programme (FP7/20072013) under REA grant agreement no PCOFUND-GA2013-606838. The authors acknowledge the support of IHE Delft lab staff in conducting various analysis.

\section{References}

[1] WHO/UNICEF, 2014. Progress on Drinking-water and Sanitation - 2014 Update, World Health Organization.

[2] United Nations, 2015. Transforming our world: the 2030 Agenda for Sustainable Development. A/RES/70/1.

[3] T. Thompson, J. Fawell, S. Kunikane, D. Jackson, S. Appleyard, P. Callan, J. Bartram and P. Kingston. Chemical Safety of Drinking Water: Assessing
Priorities for Risk Management. World Health Organization, Geneva, 2007, pp. 142.

[4] S. Chouhan, S. J. S. Flora, "Arsenic and fluoride: two major groundwater pollutants," Indian J. Exp. Biol.. vol. 48, pp. 666-678, 2010.

[5] M. A. Armienta, N. Segovia, "Arsenic and fluoride in the groundwater of Mexico," Environ. Geochem. Health, vol. 30, no. 4, pp. 345-353, 2008.

[6] C. Warren, W. G. Burgess, M. G. Garcia, "Hydrochemical associations and depth profiles of arsenic and fluoride in Quaternary loess aquifers of Northern Argentina," Mineralogical Magazine, vol. 69, no. 5, pp. 877-886, 2005.

[7] A. Salifu, B. Petrusevski, K. Ghebremichael, L. Modestus, R. Buamah, C. Aubry and G. L. Amy, "Aluminium (hydr)oxide coated pumice for fluoride removal from drinking water: Synthesis, equilibrium kinetics and mechanism," Chem. Eng. J., vol. 228, pp. 63-74, 2013.

[8] W. Li, C. Y. Cao, L. Y. Wu, M. F. Ge, W. G. Song, "Superb fluoride and arsenic removal performance of highly ordered mesoporous aluminas," J. Hazard. Mater., vol. 198, pp. 143-150, 2011.

[9] P. G. Tratnyek, R. L. Johnson, "Nanotechnologies for environmental cleanup," Nano Today, vol. 1, pp. 44-48, 2006.

[10] J. Qiao, Z. Cui, Y. Sun, Q. Hu, X. Guan, "Simultaneous removal of arsenate and fluoride from water by Al-Fe (hydr) oxides," Front. Environ. Sci. Eng., vol. 8, no. 2, pp. 169-179, 2014.

[11] T. C. Prathna. S. K. Sharma, M. Kennedy, "Development of iron oxide nanoparticle adsorbents for arsenic and fluoride removal," Desalin. Water Treat., vol. 67, pp. 187-195, 2017.

[12] A. Amirsalari and S. F. Shayesteh, "Effects of pH and calcination temperature on structural and optical properties of alumina nanoparticles," Superlattices and Microstructures, vol. 82, pp. 507-524, 2015.

[13] W. Li, C. Y. Cao, L. Y. Wu, M. F. Ge and W. G. Song, "Superb fluoride and arsenic removal performance of highly ordered mesoporous aluminas," J. Hazard. Mater., vol. 198, pp. 143-150, 2011.

[14] P. P. Diale, S. S. L. Mkhize, E. Muzenda, J. Zimba, "The sequestration of heavy metals contaminating the Wonderfonteinspruit catchment area using natural zeolite," World Academy Science Engineering Technology, vol. 5, no. 2, pp. 1-7, 2011.

[15] Y. Ku and H. M. Chiou, "The adsorption of fluoride ion from aqueous solution by activated alumina," Water Air Soil Pollut., vol. 133, pp. 349-360, 2002. 